\title{
Identification of a low tiller gene from a new plant type cultivar in rice
}

\section{(Oryza sativa L.)}

\author{
Md. Nashir Uddin ${ }^{1)}$, Asami Tomita ${ }^{1)}$, Mitsuhiro Obara ${ }^{2)}$, Seiji Yanagihara' ${ }^{2)}$ and Yoshimichi Fukuta*3) \\ 1) Graduate School of Life and Environmental Sciences, University of Tsukuba, 1-1-1 Tennodai, Tsukuba, Ibaraki 305-8572, Japan \\ 2) Japan International Research Center for Agricultural Science (JIRCAS), 1-1 Ohwashi, Tsukuba, Ibaraki 305-8686, Japan \\ 3) Tropical Agricultural Research Front, Japan International Research Center for Agricultural Science (JIRCAS), 1091 Kawarabaru, \\ Maezato, Ishigaki, Okinawa 907-0002, Japan
}

We characterized a rice introgression line, YTH34, harboring a chromosome segment from a New Plant Type (NPT) cultivar, IR65600-87-2-2-3, in the genetic background of an Indica Group elite rice cultivar, IR 64, under upland and irrigated lowland conditions in Japan. The number of panicles (as an indicator of tiller number) and number of spikelets per panicle of YTH34 were lower than those of IR 64 under irrigated lowland conditions, but both of those as well as culm length, panicle length, seed fertility, panicle weight, whole plant weight, and harvest index were dramatically reduced under upland conditions. And the low tiller of YTH34 was confirmed to start after the maximum tiller stage. In particular, the decrease of panicle number was remarkable in upland, so we tried to identify the chromosome location of the relevant gene. Through segregation and linkage analyses using $\mathrm{F}_{3}$ family lines derived from a cross between IR 64 and YTH34, and SSR markers, we found that low tiller number was controlled by a single recessive gene, ltn2, and mapped with the distance of $2.1 \mathrm{cM}$ from SSR marker RM21950, in an introgressed segment on chromosome 7. YTH34 harboring ltn2 and the genetic information for DNA markers linked will be useful for genetic modification of plant architectures of Indica Group rice cultivar.

Key Words: low tiller, introgression line, new plant type, gene mapping, rice (Oryza sativa L.).

\section{Introduction}

To break the yield barrier in Indica Group inbred cultivars, development of new plant type (NPT) rice was tried in the late 1980s at International Rice Research Institute (IRRI) (Khush 1995). The development of NPT rice at IRRI was inspired by Donald's (1968) ideotype breeding approach. The goal was to develop NPT cultivars with a yield potential $20 \%$ to $25 \%$ higher than current existing semi-dwarf rice cultivars under a tropical environment. The NPT was designed based on the results of simulation modeling and the new traits were mostly morphological since they are easier to select than physiological traits in breeding programs. The proposed NPT has a low tillering capacity (three to four tillers when direct seeded), few unproductive tillers, 200 to 250 grains per panicle, a plant height of 90 to $100 \mathrm{~cm}$, thick and sturdy stems, dark green and erect leaves, a vigorous root system, 100-130 days growth duration, and increased

\section{Communicated by Hroshi Kato}

Received August 25, 2016. Accepted October 10, 2016.

First Published Online in J-STAGE on November 23, 2016.

*Corresponding author (e-mail: zen@affrc.go.jp) harvest index (Peng et al. 1994) based on using the tropical Japonica Group's upland cultivars.

Fujita et al. (2009) developed 334 introgressions lines (INLs) by introducing chromosome segments from 10 NPT cultivars into an elite Indica-type cultivar, IR 64 . We found that several INLs with a common NPT donor, IR65600-872-2-3 (YP1), including YTH34, showed much greater reductions of agronomic trait values related to yield, including number of tillers or panicles, under upland cultivation than under irrigated lowland cultivation. The NPT cultivar, IR65600-87-2-2-3, was bred from a cross between a Chinese Japonica Group breeding line, Shen Nung 89-366, and a tropical Japonica Group upland cultivar, Ketan Lumbu (Kobayashi et al. 2010). Genotype and phenotype association mapping detected 18 quantitative trait loci (QTLs) for yield components traits on chromosome (Chr.) 7 in a segment introgressed from the NPT, suggesting that the region could play a major role in the dramatic changes in responses of agronomic traits between irrigated lowland and upland conditions, or could house a key gene that would characterize the NPT, such as low tiller or panicle number (Fig. 1A, Uddin et al. 2016).

Tillering - the production of lateral branches (culms) - is 
Mapping of a low tiller gene in rice

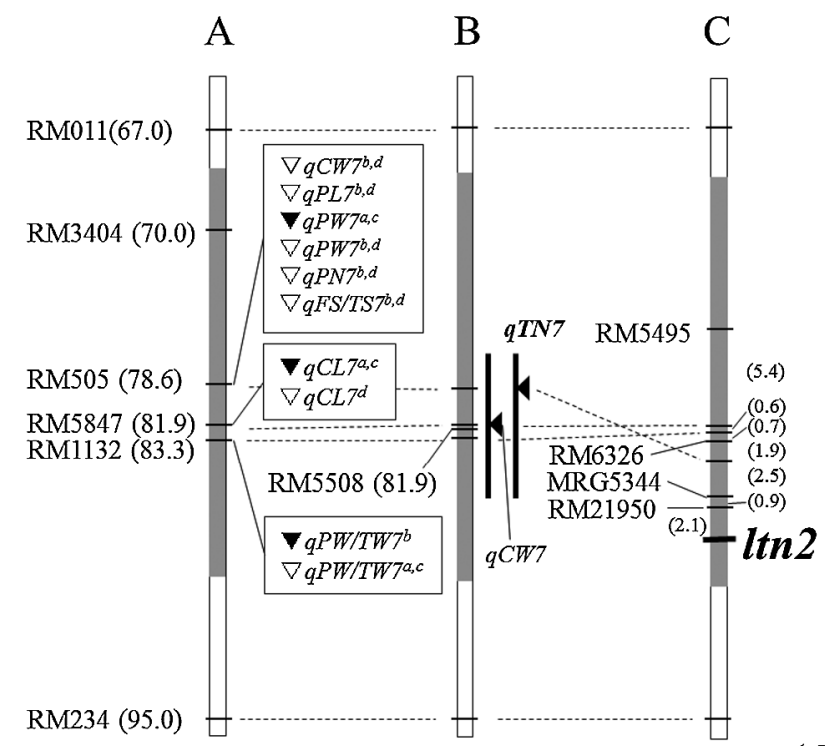

(cM)

Fig. 1. Chromosome location of low-tiller-number gene ltn2 on Chr. 7. A: Association mapping for yield components using sib-introgression lines (Fujita et al. 2009) harboring chromosome segments derived from donor parent YP1 (Uddin et al. 2016). $\nabla$ YTH34 allele decreased value in upland; $\boldsymbol{\nabla}$ YTH34 allele decreased value in irrigated lowland. CW: culm weight; PW: panicle weight; PW/TW: ratio of panicle weight to total plant weight; CL: culm length; PL: panicle length; PN: panicle number; FS/TS: ratio of fertile spikelets per panicle to total spikelets. ${ }^{\text {a }}$ Irrigated lowland in $2011 ;{ }^{\mathrm{b}}$ upland in $2011 ;{ }^{\mathrm{c}}$ irrigated lowland in 2012; d upland in 2012. B: Advanced QTL mapping using $72 \mathrm{~F}_{3}$ progeny derived from $\mathrm{F}_{2}$ plant JII-IV-10, which was heterozygous for a region on Chr. 7. Plants were grown under upland conditions. QTLs for tiller number ( $q T N 7)$ and culm weight $(q C W 7)$ were detected at five SSR marker loci. $\$ SSR marker with highest effect. C: Mapping of ltn 2 using $86 \mathrm{~F}_{3}$ family lines derived from self-pollinated $\mathrm{F}_{2}$ plants derived from IR64 $\times$ YTH34. Plants were grown under upland conditions at Ishigaki (TARF, JIRCAS) in Okinawa in 2015. ( ) A and B: Position of SSR marker in Fujita et al. (2009) and Uddin et al. (2016), respectively. C: Recombinant value between SSR markers.

an important agronomic trait that determines shoot architecture and grain production in grasses (Hussain et al. 2014). It is also a key component in the expression of phenotypic plasticity of plants in response to transient changes in growing conditions (Fujita et al. 2010). In rice, panicle number depends mainly on tiller number, and breeding cultivars with moderate to high tillering ability was an important objective in achieving higher grain yields by controlling the numbers of reproductive tillers adapting for each ecosystem for rice cultivation in the eighty's (Jennings et al. 1979, Nanda and Coffman 1979, Yoshida 1981). Then, breeders developed NPT cultivars with low tiller number but a high productive tiller ratio to improve crop adaptation in episodic drought condition and to ensure good competitiveness against weed in direct-sowing culture (Fujita et al. 2010, Khush 2000, Vergara et al. 1990).

Several genes isolated previously for tiller number through the use of mutant rice lines, including $t d r 2$
Breeding Science
Vol. 66 No. 5

(Hasegawa et al. 2005) and rcn9 (Jiang et al. 2006) on Chr. 1; OsTB1 (Takeda et al. 2003) on Chr. 3; HTD1 (Zou et al. 2005) on Chr. 4; and D3 (Ishikawa et al. 2005), MOC1 (Li et al. 2003), and rcn8 (Jiang et al. 2006) on Chr. 6, and have been associated with branching mechanisms. Fujita et al. (2010) identified a low-tiller-number gene, Ltn, on Chr. 8 in a Japanese commercial cultivar, Aikawa 1. In addition, many QTLs for number of panicles or tillers have been identified on Chrs. 2, 4, 5, and 6 (Lin et al. 1996), on Chrs. 1, 3, and 5 (Wu et al. 1998), on Chrs. 1-8 and 12 (Yan et al. 1998), on Chr. 1 (Nagata et al. 2002), on Chrs. 1, 3, 4, and 12 (Hittalmani et al. 2003), on Chrs. 2, 5, 6, and 8 (Miyamoto et al. 2004), on Chrs. 1-4, 6-9, and 12 (Liu et al. 2008, 2010, 2012), and on Chrs. 1, 2, 4-8, and 10 (Bian et al. 2013). Recently, Lyu et al. (2014) reported a candidate gene, Os07g0449700, that is critical in upland adaptation and was involved in root and shoot development, on chromosome 7.

Here, we confirm the QTLs for number of panicles or tillers on Chr. 7, detected previously by association analyses, based on advanced genetic studies using hybrid populations derived from a cross between IR 64 and YTH34, which showed unique responses in upland conditions (Uddin et al. 2016). We also discuss the relationships between the detected gene in this study with previous reports for tiller or panicle numbers, and the role of either the gene or its region on Chr. 7 .

\section{Materials and Methods}

\section{Characterization of an introgression line YTH34}

The days to heading after transplanting and yield comportments in YTH34 and IR 64 evaluated under the irrigated lowland and upland fields' conditions at Tsukuba in 2013. To confirm the occurrence of low tiller more detail during growing stage, these number of tillers or panicles of IR 64 and YTH34 were investigated from 19 days after seedling to 14 days after heading in every 7 days under the irrigated lowland condition at green house, Ishigaki, Okinawa, in 2016. The average of 5 plants of cultivars were used as the representative values in each stage.

\section{Hybrid populations for segregation analyses}

Through association analysis using 35 of the INLs developed by Fujita et al. (2009) from NPT cultivar IR65600-87-22-3 in the IR 64 background, we detected 18 QTLs for culm weight (CW: 2), panicle length (PL: 2), panicle weight (PW: 2 ), number of panicles (PN: 2), culm length (CL: 3 ), ratio of PW to total plant weight (PW/TW: 2), and ratio of number of fertile spikelets (FS) to total spikelets (FS/TS: 2), in a region on Chr. 7 near four SSR markers, RM3404, RM505, RM5847 and RM1132 (Fig. 1A, Uddin et al. 2016). The traits of several INLs, including YTH34, showed significant differences between irrigated lowland and upland conditions. In particular, the number of panicles was reduced dramatically in upland conditions. To confirm the gene or QTL on 
Chr. 7, we developed two kinds of hybrid populations from a cross between YTH34 and IR 64 (Supplemental Fig. 1).

For advanced QTL analyses, we used $72 \mathrm{~F}_{3}$ progeny generated by self-pollination of an $\mathrm{F}_{2}$ plant, JII-IV-10, which was heterozygous in the region where QTLs were detected on Chr. 7. In a tropical greenhouse at the Japan International Research Center for Agricultural Science (JIRCAS), Tsukuba, Ibaraki, Japan $\left(36^{\circ} 2^{\prime} \mathrm{N} 140^{\circ} 4^{\prime} \mathrm{E}\right)$, we grew the $72 \mathrm{~F}_{3}$ plants and the parents in containers $(50 \mathrm{~cm} \times 35 \mathrm{~cm} \times 9 \mathrm{~cm})$ in soil ( $\mathrm{pH}$ 5.0, $0.5 \mathrm{~g} \mathrm{~N}, 1.4 \mathrm{~g} \mathrm{P}, 1.3 \mathrm{~g} \mathrm{~K} \mathrm{~kg}^{-1}$, from Sumitomo Chemical Co. Japan), at a spacing of $6 \mathrm{~cm} \times 7 \mathrm{~cm}$, from January to April 2015. The plants were grown in upland conditions: from 20 days after sowing until harvest, the soil was watered to field capacity and then allowed to dry at the surface by withholding water (every 1-2 days depended on the weather conditions) to simulate 'upland' growing conditions (Pariasca-Tanaka et al. 2009). Plants were cut transversely at the soil surface and harvested at 62 days after sowing when a significant difference between parents was observed for tiller number.

For segregation analyses of tiller number and for mapping with SSR markers, we grew $86 \mathrm{~F}_{3}$ family lines generated by self-pollination of $F_{2}$ plants (Supplemental Fig. 1) in irrigated lowland and upland fields at the Tropical Agricultural Research Front (TARF), JIRCAS, Ishigaki, Okinawa, Japan $\left(24.44^{\circ} \mathrm{N}, 124.22^{\circ} \mathrm{E}\right)$, from March to July 2015 . In upland culture, twenty 4-week-old seedlings were transplanted into single row with $20 \mathrm{~cm}$ apart between hills and $60 \mathrm{~cm}$ apart between lines. In irrigated lowland culture, 22 seedlings were transplanted into two rows with $18 \mathrm{~cm}$ apart between hills and $36 \mathrm{~cm}$ apart between lines. In each field, we scored the 18 central plants by visual observation for normal or low panicle number type, and counted the number of panicles for genetic analysis at full heading stage. A total of $7.2 \mathrm{~kg} \mathrm{~N} \mathrm{ha}^{-1}$ of inorganic fertilizer was applied during soil preparation to both fields.

\section{Phenotypic evaluation}

We evaluated tiller number per plant (TN), plant length $(\mathrm{PL})$, and culm weight $(\mathrm{CW})$ in greenhouse experiment. PL was measured from the soil surface to the tip of the longest leaf. CW was determined after 5 days' oven-drying at $65^{\circ} \mathrm{C}$. The phenotypic data were used for advanced QTL analyses to confirm the results of the previous association analyses (Fig. 1A).

To test the segregation of low tiller number in $\mathrm{F}_{3}$ family lines, we calculated the average PN (as low tiller number was seen equal to low panicle number) of 18 plants per line at full heading stage in both upland and irrigated lowland culture. We determined the segregation of low tiller number in each line from the visual scoring in the upland field, and used the segregation data for SSR mapping of the low-tiller gene.

\section{QTL analysis and mapping using SSR markers}

We extracted whole genomic DNA from fresh leaves of hybrid populations as described by Wang et al. (1993) with a minor modification. Ten to twelve leaf pieces about $10 \mathrm{~mm}$ long were ground in $100 \mu \mathrm{L} \mathrm{NaOH}$ in a mixer mill MM200 (Retsch, Hann, Germany), and then 400 Tris $\cdot \mathrm{HCl}$ ( $\mathrm{pH}$ 8.0) was added and mixed well. After centrifugation, the supernatant was stored at $-20^{\circ} \mathrm{C}$. The extracted DNA was diluted $1 / 20$ with sterile water and used as a template for polymerase chain reaction (PCR) amplification with Quick Taq HS DyeMix (Toyobo, Osaka, Japan) in accordance with the manufacturer's instructions. The amplified DNA was separated by electrophoresis in $3.0 \%(\mathrm{w} / \mathrm{v})$ agarose gel containing $0.05 \%(\mathrm{v} / \mathrm{v})$ ethidium bromide. After electrophoresis, the DNA fragment was scanned with a Pharos FX (Bio-Rad, Tokyo, Japan) molecular imager for genotyping.

We found five introgressed regions in YTH34, in which 19 SSR markers on Chrs. 2 (3), 4 (2), 5 (2), 7 (10), and 8 (2) showed polymorphism between IR 64 and YTH34. We used the 10 markers on Chr. 7 for QTL analysis and linkage analysis. Single-marker analysis was performed using QTL Cartographer software ver. 2.5 (Wang et al. 2012). Recombination frequencies were analyzed by the maximumlikelihood method (Allard 1956) and converted into genetic distance by the Kosambi (1944) mapping function in Join Map v. 4.1 software.

\section{Results}

\section{Characterization of introgression line YTH34}

Under irrigated lowland conditions, panicle number (PN), total spikelets per panicle (TS), and total plant weight (TW) of YTH34 were lower than those of IR 64 at Tsukuba in 2013 (Table 1). The ratio of fertile spikelet to total spikelet (FS/TS) and panicle weight (PW) of YTH34 were higher than those of IR64, and culm length (CL), days to heading (DH), and panicle length (PL) were similar between them. Under upland conditions, PN, TS, PW, and TW of YTH34 were much lower than those of IR 64, and CL, PL, and harvest index (PW/TW) were also lower. DH and FS/TS of YTH34 were a bit higher than those of IR 64 (Table 1, Supplemental Fig. 2). These tiller numbers of IR 64 and YHT34 were similar up to 28 days after transplanting which was corresponding to maximum tiller stages, under the irrigated lowland condition of green house at Ishigaki, Okinawa. However, there were not significant differences during 35 days to 70 days after transplanting, YTH34 always showed lower tiller numbers than those of IR 64, expect for one stage of 56 days (Fig. 2).

These results indicated that the reductions of dry matter production and yield components appeared dramatically under the upland condition, and the low tiller of YTH34 occurred after the maximum tiller stage.

\section{Identification of low-tiller-number gene}

TN, CL and CW of IR 64 were $16.3,88.3 \mathrm{~cm}$ and $2.8 \mathrm{~g}$, respectively, and those of YTH183 were $11.0,86.1 \mathrm{~cm}$ and $2.1 \mathrm{~g}$, respectively in the evaluation of green house. IR 64 
Table 1. Agronomic traits of IR64 and introgression line YTH34

\begin{tabular}{|c|c|c|c|c|c|c|}
\hline \multirow{3}{*}{ Traits } & \multicolumn{6}{|c|}{ Trait value (\%) } \\
\hline & \multicolumn{3}{|c|}{ Irrigated lowland } & \multicolumn{3}{|c|}{ Upland } \\
\hline & IR64 & YTH34 & Ratio (\%) & IR64 & YTH34 & Ratio $(\%)$ \\
\hline Panicle number-PN & 22.0 & 15.0 & $(68.2)$ & 47.0 & 17.0 & $(36.2)$ \\
\hline Culm length $(\mathrm{cm})-\mathrm{CL}$ & 70.3 & 70.8 & $(100.8)$ & 51.3 & 39.9 & (77.8) \\
\hline Days to heading-DH & 107.6 & 108.3 & $(100.7)$ & 140 & 151 & $(107.9)$ \\
\hline Panicle length $(\mathrm{cm})-\mathrm{PL}$ & 25.3 & 25.9 & $(102.4)$ & 25.9 & 22.8 & $(88.0)$ \\
\hline Total spikelets - TS & 130.6 & 109.1 & $(83.5)$ & 138 & 102 & (73.9) \\
\hline Fertile seed ratio $(\%)-\mathrm{FS} / \mathrm{TS}$ & 48.2 & 85.4 & $(177.2)$ & 63.4 & 66.6 & $(105.0)$ \\
\hline Panicle weight $(\mathrm{g})$ - PW & 25.1 & 32.2 & $(128.3)$ & 51.9 & 14.6 & $(28.1)$ \\
\hline Total plant weight $(\mathrm{g})-\mathrm{TW}$ & 78.5 & 66.6 & $(84.8)$ & 140 & 48 & $(34.3)$ \\
\hline $\mathrm{PW} / \mathrm{TW}(\%)$ & 31.9 & 48.4 & $(151.7)$ & 38 & 30 & (78.9) \\
\hline
\end{tabular}

Plants were grown in irrigated lowland and upland fields in Tsukuba in 2013. Values are means of 12 plants.

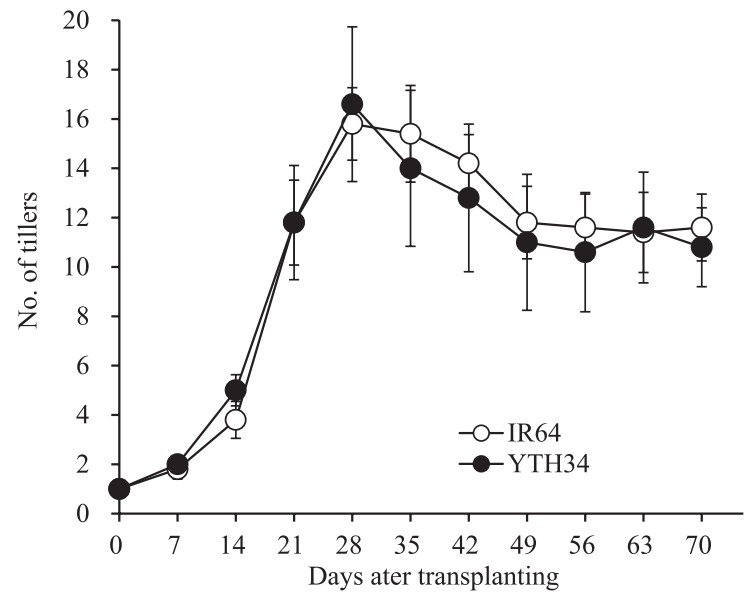

Fig. 2. Tiller or panicle numbers of IR 64 and YHT34 during the growing stages after transplanting. A rice plant after 19 days' seeding transplanted in each pot. Five plants in each cultivar were cultivated, and these means and standard deviation of tiller or panicle numbers calculated in 7 days' interval. The maximum tiller stages of IR 64 and YTH34 were around 28 days after transplanting, and thee headings of them started at 56 days after. The investigation was carried out at green house of Tropical Agricultural Research Front, JIRCAS, Ishigaki, Okinawa, in 2016. had higher trait values than YTH34, and TN and CW were recognized the significant differences $(P<0.05)$ among them. The population showed continuous distributions and transgressive segregation from IR 64 values in all traits (Fig. 3). Single-marker analysis revealed four SSR markers on Chr. 7 that were significantly associated with $\mathrm{CW}$ and TN. Among these, marker RM5847 for CW and RM505 for TN had the highest $F$ values ( 7.0 for $q C W 7$ and 6.5 for qTN7; Table 2, Fig. 1B). No associated SSRs were found for CL. These results confirm the existence of the QTLs in the introgression region on $\mathrm{Chr} .7$.

In irrigated lowland culture, PN averaged 7.5 in YTH34 and 9.5 in IR 64, and the difference was not significant (Fig. 4B). In upland culture, in contrast, PN averaged 4.0 in YTH34 and 14.6 in IR64, and the difference was significant (Fig. 4A). The average $\mathrm{PN}$ in each $\mathrm{F}_{3}$ family varied from 3 to 17 in upland culture and from 7 to 13 in lowland culture (Fig. 4). In particular, the distribution of $\mathrm{F}_{3}$ lines in upland culture showed a division into low and normal PN at 8 panicles, and there were more high-PN lines. The=segregation in each $\mathrm{F}_{3}$ line was investigated and confirmed under the upland field. The segregation ratio of the 21 low-PN homozygote, 48 heterozygote, and 17 normal-PN homozygote lines fitted a 1:2:1 ratio $\left(\chi^{2}=1.25, P=0.465\right.$; Table 3). These results indicate that the low-PN (an indicator of low
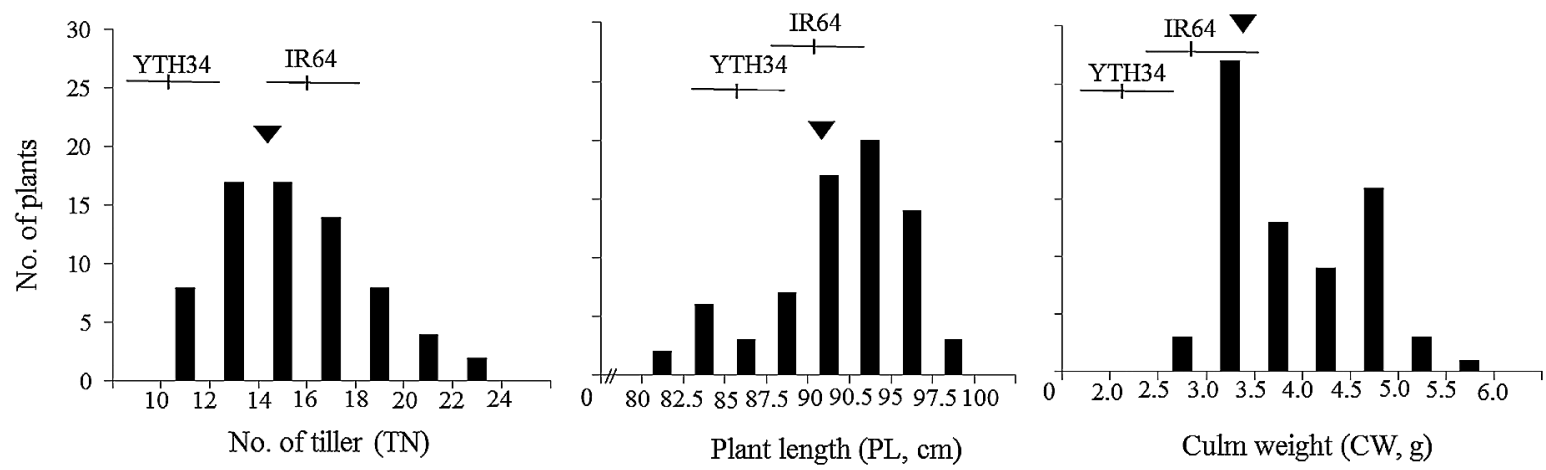

Fig. 3. Segregation of tiller number, plant length, and culm weight of $72 \mathrm{~F}_{3}$ progeny derived from an $\mathrm{F}_{2}$ plant heterozygous for a region on Chr. 7 where a QTL for panicle number was detected. Plants were grown in a greenhouse under upland conditions in 2015 . $\boldsymbol{\nabla}$ Average of hybrid population. - $\mid$ - Range and average of parent cultivars. 
Table 2. Effects of QTLs detected by advanced QTL analysis

\begin{tabular}{cccccccc}
\hline \hline Trait & $\begin{array}{c}\text { Designation } \\
\text { of QTL }^{a}\end{array}$ & $\begin{array}{c}\text { Marker } \\
\text { associated } \\
\text { with trait }\end{array}$ & Chr. & $\begin{array}{c}\text { Position } \\
(\mathrm{cM})^{b}\end{array}$ & $F$ & $R^{2}$ & Additive $^{c}$ \\
\hline CW & $q C W 7$ & RM505 & 7 & 78.6 & 7.0 & 9.6 & 0.27 \\
& RM5847 & 7 & 81.6 & 7.0 & 9.6 & 0.30 \\
& RM5508 & 7 & 81.9 & 6.9 & 9.4 & 0.30 \\
& RM1132 & 7 & 83.3 & 6.3 & 8.5 & 0.29 \\
\hline \multirow{T}{*}{ TN } & qTN7 & RM505 & 7 & 78.6 & 6.5 & 8.6 & 1.25 \\
& & RM5847 & 7 & 81.6 & 6.3 & 8.1 & 1.16 \\
& RM5508 & 7 & 81.9 & 6.2 & 8.3 & 1.20 \\
& & RM1132 & 7 & 83.3 & 5.5 & 7.5 & 1.07 \\
\hline
\end{tabular}

Single-marker association analysis $(P \leq 0.05)$ of SSR markers with traits in $72 \mathrm{~F}_{3}$ plants derived by self-pollination of an $\mathrm{F}_{2}$ plant heterozygous for a region on Chr. 7.

${ }^{a}$ QTLs were designated following standard QTL nomenclature.

${ }^{b}$ Position according to Fujita et al. (2009).

${ }^{c}$ Positive values indicate that IR64 allele increases trait value.

tiller number) trait in the $\mathrm{F}_{3}$ family lines was controlled by a single recessive gene. We designated this novel low-TN gene $\operatorname{ltn} 2$, because there are previous no reports of TN genes in this region on Chr. 7.

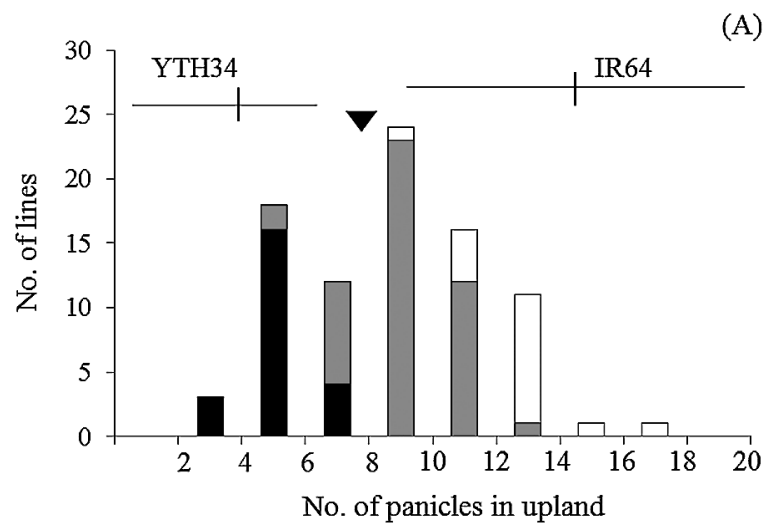

Table 3. Segregation of $F_{3}$ family lines derived from IR $64 \times$ YTH34

\begin{tabular}{|c|c|c|c|c|c|}
\hline \multicolumn{4}{|c|}{ No. of lines } & \multirow{2}{*}{$\begin{array}{c}\chi^{2} \\
(1: 2: 1)\end{array}$} & \multirow{2}{*}{$\begin{array}{c}P \\
(\%)\end{array}$} \\
\hline $\begin{array}{l}\text { Low-tiller } \\
\text { homozygote }\end{array}$ & Heterozygote & $\begin{array}{l}\text { Normal-tiller } \\
\text { homozygote }\end{array}$ & Total & & \\
\hline 23 & 47 & 16 & 86 & 1.88 & 0.389 \\
\hline
\end{tabular}

Plants were grown in an upland field at Tropical Agricultural Research Front, JIRCAS, Ishigaki in Okinawa in 2015.

Co-segregation and linkage analysis between $l t n 2$ and SSR markers mapped ltn 2 at $2.1 \mathrm{cM}$ from marker RM21950 (Fig. 1C). The graphical genotypes of $\mathrm{F}_{3}$ lines were investigated using two non-polymorphism SSR markers, RM1279 and RM21952 and 7 polymorphism markers on chromosome 7 between IR 64 and YTH34 (Fig. 5). All low tiller homozygote lines showed homozygote in MRG5344 and RM21950, among the 7 SSR markers, commonly. One heterozygote line harbored homozygote of introgression chromosome in all SSR markers. These results indicated that ltn2 located between SSR markers RM21950 and RM21952.
(A)

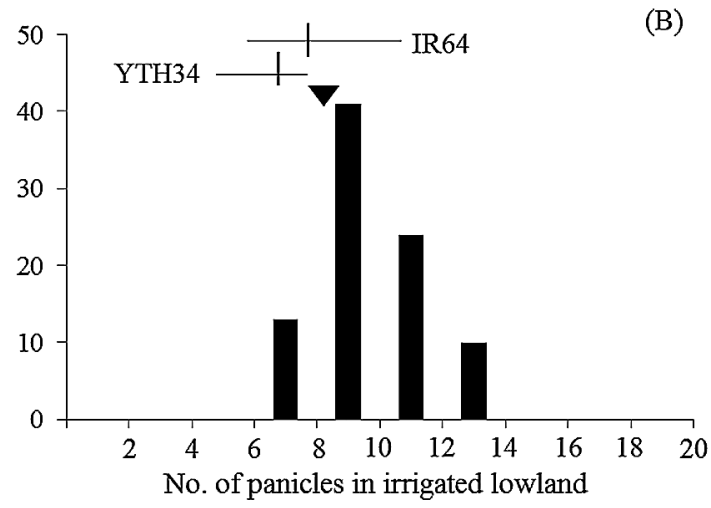

Fig. 4. Segregation of panicle number in $86 \mathrm{~F}_{3}$ family lines derived by self-pollination of $\mathrm{F}_{2}$ plants, in (A) upland and (B) irrigated lowland conditions. Values are means of 18 plants per line. Black: low-PN homozygote lines, Gray: heterozygote lines, White: normal-PN homozygote lines

$\boldsymbol{\nabla}$ : Average of hybrid population, - — —: Range and average of parent varieties.

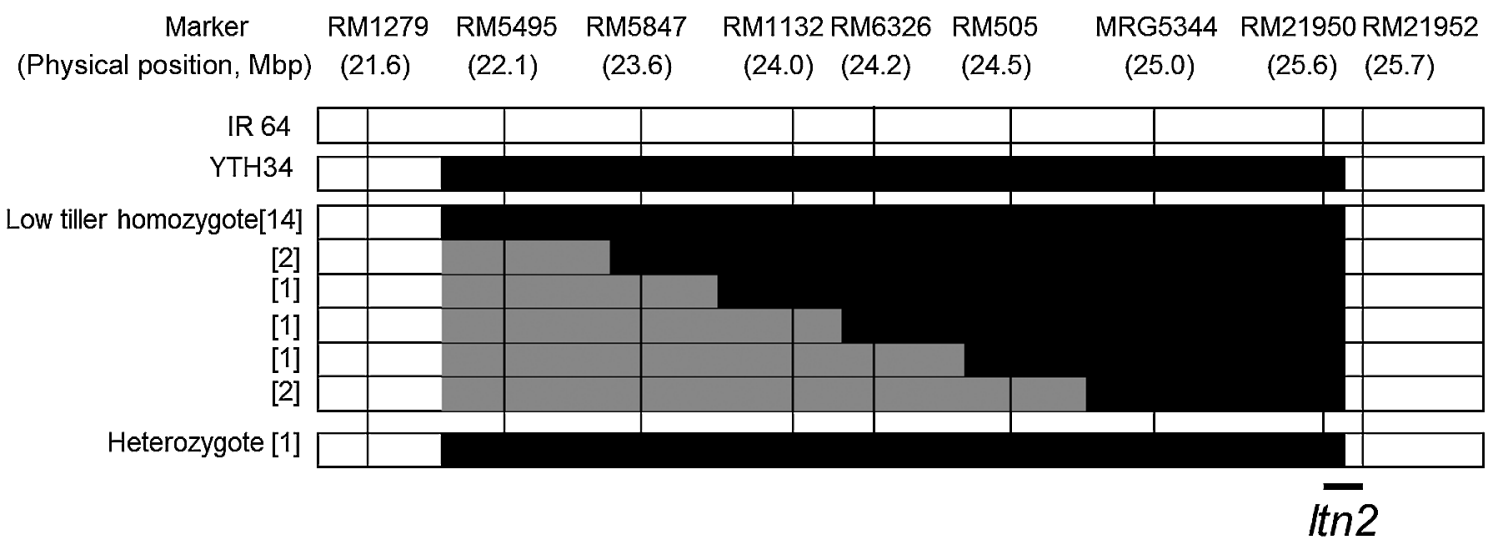

Fig. 5. Physiological position of $l t n 2$ on chromosome 7. Low tiller gene $l t n 2$ was estimated to locate between $R M 21950$ and $R M 21952$, based on the genotypes of $\mathrm{F}_{2}$ individuals and phenotypic data in $\mathrm{F}_{3}$ family lines derived from a cross between IR64 and YHT34. YTH34 harbors the chromosome introgression from a donor cultivar, IR65600-87-2-2-3 (YP1), between SSR markers RM5495 to RM21950. White, gray and black regions in graphical genotypes indicate the homozygote of IR 64 , heterozygote and homozygote of introgressed segments, respectively. [ ]: No. of $\mathrm{F}_{3}$ lines. 


\section{Discussion}

Several INLs, including YTH34, from the same donor NPT (YP1) in the IR 64 genetic background, had dramatically different phenotypes between lowland and upland conditions, compared to IR 64, and eighteen QTLs for yield traits, including PN, had been identified on Chr. 7 by association analyses in a previous study (Uddin et al. 2016) (Fig. 1A). Here, we confirmed the differences between IR 64 and YTH34 under lowland and upland conditions in the field in Tsukuba in 2013, in a greenhouse in Tsukuba in 2015, and in the field in Ishigaki in 2015 (Table 1, Figs. 2, 3, 4, Supplemental Fig. 2). We could demonstrate again that the low tiller numbers in TYH34 occurred under broth conditions, irrigated lowland and upland, and particularly it appeared dramatically under the upland condition. Moreover, the low tiller was confirmed to start after the maximum tiller stage, as a new finding (Fig. 2).

The location of a QTL for low TN was confirmed in a region on Chr. 7 introgressed from the NPT where several QTLs were previously detected by association analysis (Fig. 1B, Table 2) and advanced QTL analysis. The QTL segregated as a single recessive gene (Table 3 ), which we designated ltn2 (Fig. 1C). Several genes for tillering have been reported previously on Chrs. 1, 3, 4, 6 and 8, as described in the Introduction, but not on Chr. 7.

The ltn 2 region on Chr. 7 produced unique trait responses in upland conditions: low tiller number, low dry matter production, low spikelet number, short panicle and culm lengths (Tables 1, 2). These results suggest that ltn2 or some genes play an important role in the response to upland conditions. Previous studies reported QTLs for tolerance to cold stress (Zhou et al. 2010), tolerance to high temperature stress (Murata et al. 2014), seed shape (Qiu et al. 2012), higher spikelet number (Koide et al. 2013), and high TN (Thomson et al. 2003) in this region, linked to the SSR markers RM1132 and RM505, in irrigated lowland culture. Lyu et al. (2014) found upland-specific, ecotype-differentiated genomic regions and identified a candidate gene $(O s 0790449700)$ for relating with shoot and root development in a region on $\mathrm{Chr} .7$ under drought stress. The region on Chr. 7 corresponds with those previous reports. The QTL for low tiller on Chr.7 in an introgression line YTH34 was confirmed by advance QTL analysis using $\mathrm{F}_{3}$ progenies derived from the self-pollination of one heterozygote $F_{2}$ plant, and it was identified as a single recessive gene, $\operatorname{ltn} 2$ in $\mathrm{F}_{3}$ family lines derived from the cross between IR 64 and YTH34. To confirm the effect of ltn2, and the relationships with QTLs or genes reported in previous reports (Koide et al. 2013, Lyu et al. 2014, Murata et al. 2014, Qiu et al. 2012, Thomson et al. 2003, Zhou et al. 2010), we will need to develop isogenic lines and characterize them in more detailed physiological and genetic studies. Particularly, Lyu et al. (2014) detected a QTL for short and root on similar region of Chr.7 and found a candidate gene (Os07g0449700), and estimated that it contributed to the differentiation or adaptation between lowland and upland. The QTL for culm weight, $q C W 7$, in $\mathrm{F}_{3}$ progenies and ltn2 in $\mathrm{F}_{3}$ Family lines, were detected on the same region of Chr.7 in our study (Fig. 1B, 1C). The relationships among three genetic factors, Os07g0449700, qCW7 and ltn2, and the multiple effect(s) of ltn2, will need to confirm.

We suspect that the segment on Chr. 7 originated from the upland cultivar Ketan Lumbu, but this needs to be confirmed. Even though the effects of ltn2 or the other QTLs on Chr. 7 reduce dry matter production under upland conditions, these genes or QTLs might play key roles in differentiating lowland and upland cultivars or in adaptations to the different conditions. In the upland condition, these rice cultivars characterized by the low tillering, heavy panicle and short mature, have been cultivated to avoid the risk of short water apply under rainfed condition and to maintain the yield product by minimalizing of reproductive tillers. The unique plant architecture of low tiller/panicle may be the first priority trait for adaptation to the serious environmental conditions such as upland. It means that ltn 2 related with the adaptation of rice cultivar to upland, and it may be useful for genetic improvement of rice cultivars under upland or unfavorable conditions with the other genetic factors.

YTH34 has the genetic background of an elite Indica Group cultivar IR 64 and was published as an open material by Fujita et al. (2009). TTH34 and the genetic information of ltn 2 will be able to use for the genetic improvement or modification of plant architecture of Indica Group cultivar, directly, and to understand the genetic mechanism for differentiation between lowland and upland ecotypes or adaptation to upland condition.

\section{Acknowledgements}

This study was conducted within the JIRCAS research project "Rice Innovation for Environmentally Sustainable Production Systems" from 2011 to 2015, and the IRRI-Japan Collaborative Research Project (Phases IV, V and VI), funded by the Ministry of Agriculture, Forestry and Fisheries, Japan, from 1999 to 2015.

\section{Literature Cited}

Allard, R.W. (1956) Formulas and tables to facilitate the calculation of recombination values in heredity. Hilgardia 24: 235-278.

Bian, J., H.He, H.Shi, C.Zhu, X.Peng, C.Li, J.Fu, X.He, L.Hu, X. Chen et al. (2013) Dynamic QTL detection and analysis of tiller number before and after heading in japonica rice. Aust. J. Crop Sci. 7: $1189-1197$

Donald,C.M. (1968) The breeding of crop ideotypes. Euphytica 17: 385-403.

Fujita,D., R.E. Santos, L.A.Ebron, M.J. Telebanco-Yanoria, H. Kato, S. Kobayashi, Y.Uga, E.Araki, T.Takai, H.Tsunematsu et al. (2009) Development of introgression lines of an Indica-type rice variety, IR64, for unique agronomic traits and detection of the responsible chromosomal regions. Field Crops Res. 114: 244-254.

Fujita, D., L.A.Ebron, E.Araki, H.Kato, G.S.Khush, J.E. Sheehy, 
T. Lafarge, Y. Fukuta and N. Kobayashi (2010) Fine mapping of a gene for low-tiller number, Ltn, in japonica rice (Oryza sativa L.) variety Aikawa 1. Theor. Appl. Genet. 120: 1233-1240.

Hasegawa,Y., E. Yamamoto, M.Ashikari, T. Sazuka, A.Miyao, H. Hirochika, H. Kitano and M. Matsuoka (2005) Characterization and mapping of tillering dwarf rice 2, tdr2. Rice Genet. News. 22: 48.

Hittalmani, S., N. Huang, B. Courtois, R. Venuprasad, H.E. Shashidhar, J.Y.Zhuang, K.L.Zheng, G.F.Liu, G.C.Wang, J.S.Sidhu et al. (2003) Identification of QTL for growth and grain yield-related traits in rice across nine locations of Asia. Theor. Appl. Genet. 107: 679-690.

Hussain,A., E.Tavakol, D.S.Horner, M.Munoz-Amatriain, G.J. Muehlbauer and L. Rossini (2014) Genetics of tillering in rice and barley. Plant Genome 7(1).

Ishikawa, S., M. Maekawa, T.Arite, K.Onishi, I.Takamura and J.Kyozuka (2005) Suppression of tiller bud activity in tillering dwarf mutants of rice. Plant Cell Physiol. 46: 79-86.

Jennings, P.R., W.R. Coffman and H.E. Kaufman (1979) Rice improvement. International Rice Research Institute. Manilla, the Philippines.

Jiang, G.H., L.B. Guo, D.W.Xue, D.L.Zeng and G.H.Zhang (2006) Genetic analysis and gene-mapping of two reduced-culm- number mutants in rice. J. Integr. Plant Biol. 48: 341-347.

Khush, G.S. (1995) Breaking the yield frontier of rice. GeoJournal 35: 329-332.

Khush, G.S. (2000) New plant type of rice for increasing the genetic yield potential. In: Nanda, J.S. (ed.) Rice breeding and Genetics. Science Publishers, Enfield (NH), pp. 99-108.

Kobayashi, N., Y.Fukuta and O. Ito (2010) JIRCAS Working Report No. 66: 6.

Koide, Y., D. Fujita, G.A. Tagle, K. Sasaki, T. Ishimaru, Y. Fukuta and N.Kobayashi (2013) QTL for spikelet number from a highyielding rice variety, Hoshiaoba, detected in an introgression line with the genetic background of an indica rice variety, IR64. Euphytica 192: 97-106.

Kosambi,D.D. (1944) The estimation of map distances from recombination values. Ann. Eugen. 12: 172-175.

Li, X., Q. Qian, Z.Fu, Y.Wang, G.Xiang, D.Zeng, X.Wang, X.Liu, S. Teng, F. Hiroshi et al. (2003) Control of tillering in rice. Nature 422: 618-621.

Lin, H.X., H.R. Qian, J.Y.Zhuang, J.Lu, S.K.Min, Z.M.Xiong, N. Huang and K.L.Zheng (1996) RFLP mapping of QTLs for yield and related characters in rice (Oryza sativa L.). Theor. Appl. Genet. 92: 920-927.

Liu, G., Z.M.Zhang, H.T.Zhu, F.M.Zhao, X.H.Ding, R.Z.Zeng, W.T.Li and G.Q.Zhang (2008) Detection of QTLs with additive effects and additive-by-environment interaction effects on panicle number in rice (Oryza sativa L.) by using single segment substituted lines. Theor. Appl. Genet. 116: 923-931.

Liu, G., H.Zhu, S. Liu, R. Zeng, Z.Zhang, W.Li, X.Ding, F.Zhao and G.Zhang (2010) Unconditional and conditional QTL mapping for the developmental behavior of tiller number in rice (Oryza sativa L.). Genetica 138: 885-893.

Liu, G., H.Zhu, G.Zhang, L.Li and G. Ye (2012) Dynamic analysis of QTLs on tiller number in rice (Oryza sativa L.) with single segment substitution lines. Theor. Appl. Genet. 125: 143-153.

Lyu, J., B.Li, W.He, S.Zhang, Z.Gou, J.Zhang, L.Meng, X.Li, D. Tao, W. Huang et al. (2014) A genomic perspective on the important genetic mechanisms of upland adaptation of rice. BMC plant Biol. 14: 160.

Miyamoto, N., Y. Goto, M. Matsui, Y.Ukai, M. Morita and K. Nemoto (2004) Quantitative trait loci for phyllochron and tillering in rice. Theor. Appl. Genet. 109: 700-706.
Murata, K., Y. Iyama, T. Yamaguchi, H. Ozaki, Y. Kidani and T. Ebitani (2014) Identification of a novel gene (Apql) from the indica rice cultivar 'Habataki' that improves the quality of grains produced under high temperature stress. Breed. Sci. 64: 273-281.

Nagata, K., Y.Fukuta, H. Shimizu, T. Yagi and T. Terao (2002) Quantitative trait loci for sink size and ripening traits in rice (Oryza sativa L.). Breed. Sci. 52: 259-273.

Nanda, J.S. and W.R. Coffman (1979) Alternative plant types and other agronomic characteristics for rainfed lowland rice. In: Rainfed Lowland Rice, selected papers from the 1978 International Rice Research Conference. International Rice Research Institute, Manilla, the Philippines, pp. 23-133.

Pariasca-Tanaka, J., K. Satoh, T.Rose, R. Mauleon and M.Wissuwa (2009) Stress response versus stress tolerance: a transcriptome analysis of two rice lines contrasting in tolerance to phosphorus deficiency. Rice 2: 167-185.

Peng, S., G.S. Khush and K.G. Cassman (1994) Evolution of the new plant ideotype for increased yield potential. In: Cassman, K.G. (ed.) Breaking the yield barrier. IRRI, Los Baños, Philippines, pp. 5-20.

Qiu, X., R. Gong, Y.Tan and S.Yu (2012) Mapping and characterization of the major quantitative trait locus qSS7 associated with increased length and decreased width of rice seeds. Theor. Appl. Genet. 125: 1717-1726.

Takeda,T., Y.Suwa, M.Suzuki, H.Kitano, M.Ueguchi-Tanaka, M.Ashikari, M. Matsuoka and C. Ueguchi (2003) The OsTB1 gene negatively regulates lateral branching in rice. Plant J. 33: 513-520.

Thomson, M.J., T.H.Tai, A.M.McClung, X.-H.Lai, M.E.Hinga, K.B.Lobos, Y.Xu, C.P.Martinez and S.R.McCouch (2003) Mapping quantitative trait loci for yield, yield components and morphological traits in an advanced backcross population between Oryza rufipogon and the Oryza sativa cultivar Jefferson. Theor. Appl. Genet. 107: 479-493.

Uddin, M.N., M. Obara, S. Yanagihara, T. Ishimaru, N.Kobayashi and Y.Fukuta (2016) Genetic characterization of introgression lines with the genetic background of the Indica-type rice $(O$. sativa $\mathrm{L}$.) cultivar IR64 under irrigated lowland and upland. Field Crops Res. 191: 168-175.

Vergara, B.S., B. Venkateswarlu, M.Janoria, J.K.Ahn, J.K. Kim and R.M. Visperas (1990) Rationale for a low-tillering rice plant type with high density grains. Philippines J. Crop Sci. 15: 33-40.

Wang, H., M. Qi and A.S.Culter (1993) A simple method of preparing plant samples for PCR. Nucleic Acids Res. 21: 4153-4154.

Wang, S., C.J.Basten, P. Gaffney and Z.B.Zeng (2012) Windows QTL Cartographer 2.5. User Manual. Bioinformatics Research Center, North Carolina State Univ., Raleigh, NC.

Wu, W.R., W.-M.Li, D-Z.Tang, H-R.Lu and A.J.Worland (1998) Time-related mapping of quantitative trait loci underlying tiller number in rice. Genetics 151: 297-303.

Yan, J.Q., J.Zhu, C.X.He, M.Benmoussa and P.Wu (1998) Quantitative trait loci analysis for the developmental behavior of tiller number in rice (Oryza sativa L.). Theor. Appl. Genet. 97: 267-274.

Yoshida, S. (1981) Fundamentals of rice crop science. International Rice Research Institute, Manilla, the Philippines.

Zhou, L., Y.Zeng, W.Zheng, B. Tang, S. Yang, H.Zhang, J. Li and Z. Li (2010) Fine mapping a QTL $q C T B 7$ for cold tolerance at the booting stage on rice chromosome 7 using a near-isogenic line. Theor. Appl. Genet. 121: 895-905.

Zou,J., Z.Chen, S.Zhang, W.Zhang, G.Jiang, X.Zhao, W.Zhai, X.Pan and L.Zhu (2005) Characterizations and fine mapping of a mutant gene for high tillering and dwarf in rice (Oryza sativa L.). Planta 222: 604-612. 